\title{
Kıyı Sedimentlerinde Tane Boyunu Etkileyen Faktörler: Antalya Körfezi'nde Konyaaltı ve Lara Plajlarının (Antalya) Karşılaştırılması
}

\author{
The Factors Affecting Grain Size of Coastal Sediments: Comparison between Konyaaltı and \\ Lara Beaches (Antalya) in Gulf of Antalya
}

\section{Koray KOÇ, Erdal KOŞUN, M. Erkan KARAMAN}

Akdeniz Üniversitesi, Mühendislik Fakültesi, Jeoloji Mühendisliği Bölümü, 07058, Antalya

(e-posta:koraykoc@akdeniz.edu.tr)

\section{ÖZ}

Konyaaltı ve Lara plajları Antalya ilinin merkezi sınırları içerisinde ve Antalya Körfezi'nin sırasıyla kuzeybatı ve kuzeydoğu kesimlerinde yer almaktadırlar. Bu çalışmada aynı hidrodinamik koşullar altında görünen bu iki plajın, detaylı tane boyu özellikleri karşılaştırılmıştır. Konyaaltı plajında ortalama tane boyu -3,50 $\phi$ ile 0,82 $\phi$ arasında değişirken, Lara plajında bu değerler -0,43 $\phi$ ile 1,81 $\phi$ arasında değerler almaktadır. Konyaaltı plajında doğu yönlü taşınmaya bağlı olarak tane boyunda artış söz konusu iken, bu tip bir değişim Lara plajında gözlenmemiştir. Boylanma durumu ise tane boylarına bağlı olarak Konyaaltı plajında iyi derecede boylanma, Lara plajında ise çoğunlukla kötü boylanma tespit edilmiştir. Elde edilen sonuçlar doğrultusunda plajların sınıflaması yapılarak, plajlarda tespit edilen özelliklerin, kıyı boyu akıntı ve beslenme alanı ile ilişkili farklılıkları tartışılmıştır.

Anahtar Kelimeler: Antalya, Konyaaltı plaj1, Lara plaj1, sedimantoloji, tane boyu

\section{ABSTRACT}

The Konyaalt and Lara beaches are located in the center of Antalya, to the northeast and northwest parts of Gulf of Antalya, respectively. In this study, the grain size features of two beaches which control under the same hydrodynamic conditions were compared within detail. While the mean grain size in the Konyaalt beach vary from -3,50 $\phi$ to 0,82 $\phi$, in the Lara beach it ranges between -0,43 $\phi$ and 1,81 $\phi$. There is increasing in the grain size depend on eastward transportation in the Konyaaltı beach, however similar 
changes cannot observe in the Lara beach. Sorting parameter that determined in the Konyaalt and Lara beach represent well sorted and mostly poorly sorted, respectively. According to the results obtained from these two beaches, they were defined within coastal classification, and relationship between grain size parameters, longshore current and catchment area was discussed.

Key words: Antalya, Konyaalt beach, grain size, Lara beach, sedimentology

\section{GİRİŞ}

Sedimantolojik incelemelerde, ortalama tane boyu (Mz), boylanma (So), çarpıklık (Sk) ve tepelenme (Kg) gibi fiziksel parametrelerin, taşınma şekline ve depolanma ortamına göre farkl11ıklar gösterdiği üzerine birçok çalışma mevcuttur (örn. Folk ve Ward, 1957; Friedman, 1967; Visher, 1969). Ancak benzer hidrodinamik koşulların farklı ortamlarda oluşabilmesinden dolayı, bu parametreler ile ilgili yorumlama yapılırken dikkatli olunması gerektiği değişik yazarlarca vurgulanmıştır (örn. Reineck ve Singh, 1980). Bu çalışma kapsamında bu parametreler kıyı ortamında incelenmiştir. Kıyılar erozyonal ya da birikimli olmak üzere ikiye ayrllır. $\mathrm{Bu}$ iki farklı tip kıyının hidrolik özellikleri farklıdır ve aşınma ya da birikmeye bu özellikleri karar verir. Hidrolik özelliklerden birisi olan hidrolik iletkenlikte sediman boyuna hassas bir şekilde bağlıdır. $\mathrm{Bu}$ bağlamda yüzey sedimanlarının konumsal dağılımı, düşey yönde tane boyunun değişimi hidrolik açısından çakıllı plajlar için önemlidir (Buscombe ve Masselink, 2006). Bir diğer husus karışık plajlarda erozyon ve taşkınlara karşı koruma görevi görürler (Horn ve Walton, 2007). Horn ve Walton (2007), plajlarda yapılan yenileme çalışmalarında kullanılan malzemenin normalde olandan daha fazla ince sediman içerdiğini ve bunun tane boyu dağılımını, boylanmayı ve hidrolik iletkenliği önemli ölçüde bozduğunu vurgulamıştır.

Son y1llarda modern plaj yüzeylerinde gerçekleştirilen çalışmalarda, güncel kıyı çizgisine paralel ve dik olacak şekilde çakıl boyutundaki malzemenin taşınımına (Bartholoma vd., 1998;
Muzuka ve Shaghude, 2000; Ivamy ve Kench, 2006; Horn ve Walton, 2007; Osborne, 2005; Dickson vd., 2011) çoğu kez dikkat çekilmiştir. Bunlara ek olarak Jennings ve Schulmeister (2002) tarafindan oluşturulan ve literatürde sıkça kullanılan bir plaj sinıflaması da mevcuttur. Bu sinıflamaya göre üç farklı plaj tipi vardır ve bunlar; tamamen çakıldan oluşan plajlar (pure gravel beach), kum ve çakıl karışık plajlar (mixed sand and gravel beach) ve üçüncüsü kompozit plajlar (composite beach)dan oluşmaktadır. Bu çalışma kapsamında ele alınan Antalya merkezindeki Konyaaltı ve Lara plajları ile ilgili olarak eğer literatür incelenirse, bu plajlardaki genel sedimantolojik doku ve buna bağlı bu plajların sınıflaması ile ilgili olarak çok az bilgi olduğu görülecektir. Bu çalışmalardan en önemlisi olan Ergin vd. (2007), Antalya Körfezi'nde genel olarak plajlardaki ağır mineral içeriğini incelemiş ve bu kapsamda plajlardaki sediman dağılımından yola çıkarak genel bir sınıflama yapmıştır.

$\mathrm{Bu}$ çalışmanın amacı ise daha küçük ölçekte bahsedilen iki plajı ele alarak, kıyı gerisi sedimanların fiziksel özelliklerini ayrıntılı bir biçimde çıkarmaktır. En sonunda ise plajlarda dokusal parametreler arasında ne tür farklilıklar olduğu, bu farklılıkların ana nedenleri ve bunların sonucunda Konyaaltı ve Lara plajının hangi tür plaj sınıfına girdiği araştırılmıştır. Böylece Antalya merkezinde yer alan iki önemli plajın fiziksel özellikleri ortaya çıkarılmış, literatürde ki eksikliğin bir kısmı giderilmiş, bu alanlarda yapılacak düzenlemelerde göz önünde bulundurulması gereken parametreler belirlenmiştir. 


\section{Jeolojik ve Jeomorfolojik Özellikler}

Çalışmanın konusunu oluşturan Konyaaltı plaj1 Antalya Körfezi'nin kuzeyinde şehir merkezinin batısında, Lara plajı ise doğuda yer almaktadır (Şekil 1). Bölgeyi batısında ve kuzeyinde batı Toroslar sinırlamaktadır. Batıdaki Konyaaltı plajının hemen gerisinde Toroslar yükselmektedir. Bu da kıyı gerisindeki alanın yüksek bir topoğrafyaya sahip olmasına neden olmaktadır. Lara plajının gerisinde geniş düzlükler ve kumullar yer almaktadır. Konyaaltı plajına gelen sedimanlar çoğunlukla Boğaçay ve Karaman Deresi tarafindan getirilmekte, bu akarsular Antalya naplarını (Levefre, 1967) dolaşarak kıyıya ulaşmaktadır. Coğrafik konum incelendiğinde, Antalya naplarının kıyıya gelen malzemenin ana kaynağı olduğu görülmektedir (Şekil 1). Antalya napları en alttan üste doğru Çataltepe nap1, Alakırçay napı, Tahtalıdă̆ nap1 ve Tekirova napından oluşmaktadır (Şenel, 1997). Naplar genellikle neritik kireçtaş1, marn, kumtaşı, kiltaşı, radyolarit, çört, spilitik bazalt ve şeyllerden oluşmaktadır (Şenel, 1997; Poisson vd., 2003). Konyaaltı plajında yapılan çalışmalarda çokça gabro, radyolarit, peridotit çakılları örneklenmiştir. Bunların kaynağı Antalya naplarının en üst grubu olan Tekirova ofiyolit napıdır (Şenel, 1997). Konyaaltı ve Lara plajlarının hemen ortasında yer alan falezler ise Antalya tufasının (Koşun, 2012) ürünüdür. Yaklaşık $630 \mathrm{~km}^{2}$ yayılıma sahip olan tufa yine plajlara sediman sağlayan diğer bir elemandır. Lara plajına gelindiğinde, gerisinde geniş düzlükler olup, kumullar bulunmaktadır. Lara plajında çalışma bölgesine en yakın akarsu Aksu çayıdır. Kıyıya ulaşan malzeme çoğunlukla bu akarsu ile taşınmaktadır. Antalya Körfezi'nin bu bölümüne kıyıya ulaşan sedimanların ana kaynağı Antalya Miyosen Havzası'dır. Kısmen Alanya metamorfik naplarından da aşınma ürünü sedimanların geldiği söylenebilir. Antalya Miyosen havzası üç alt havzaya ayrılır ve Miyosen ile Pliyosen yaşl1 klastikler, mercan resifleri, resifal şelf karbonatlarından meydana gelir (Çiner vd., 2008). Alanya napları ise Kambriyen-Eosen yaş aralığındaki kayaçlardan meydana gelir ve Sugözü nap1, Mahmutlar nap1 ile Yumrudağ nap1 olmak üzere üç metamorfik naptan oluşur (Kansun ve Baş, 2002; Ergin vd., 2004). 


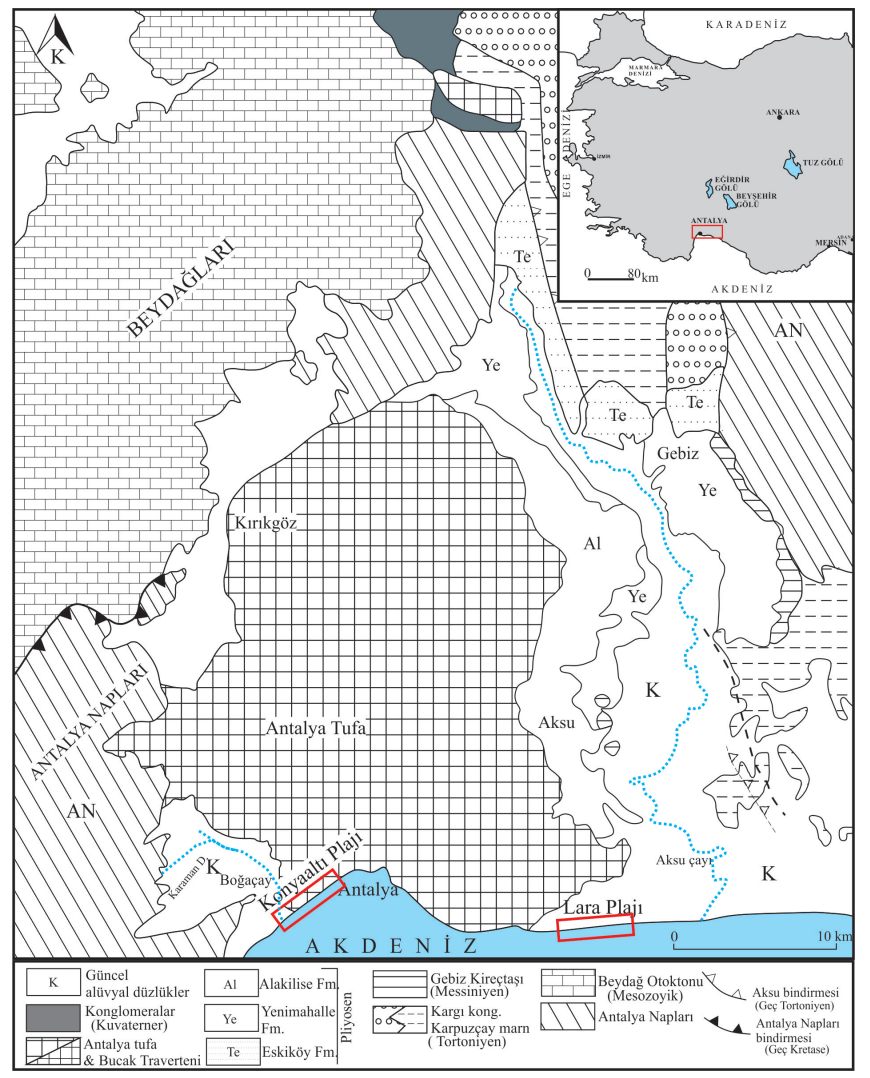

Şekil 1. Konyaaltı plajı ve Lara plajının yerleri ve Antalya bölgesinin jeoloji haritası (Koşun 2012'den değiştirilerek alınmıştır)

Figure 1. Geological map of the Antalya region showing the Konyalat and Lara beach locations (modified from Koşun 2012)

\section{Hidrodinamik Özellikler}

Antalya Körfezi'ne sediman taşıyan çok sayıda akarsu bulunmaktadır. Bunlar ile ilgili olarak ise sinırlı sayıda veri mevcuttur. İnceleme alanları açısından ayrıca öneme sahip akarsular mevcuttur. Bunlar batıda Boğaçay ve Karaman Deresi, doğuda ise Aksu çayıdır (Şekil 1). Boğaçay 48 km uzunluğundadır ve $968 \mathrm{~km}^{2}$ lik drenaj havzasına sahiptir. Taşınan sediman miktarı ile ilgili veri mevcut değildir. Aksu çayı ise Boğaçay'ın aksine daha uzun olup 117 km uzunluğundadır. Drenaj havzası $5582 \mathrm{~km}^{2}$ ve günlük taşınan sediman miktarı 21963 tona çıkabilmektedir (Ergin vd., 2007). Bunların dışında yine çok sayıda akarsu bulunmakta fakat genellikle mevsimliktir.
Doğu Akdeniz akıntı sistemi içerisinde yer alan Antalya Körfezi'nde akıntı tipi genel rejime uygun biçimde girdap (siklonik) şeklindedir (Robinson vd., 1992). Kıyılarda akıntı yönü ise genellikle doğu yönlüdür. Y1l içerisinde akıntı yön ve şiddetlerinde önemli ölçüde değişim görülmektedir (Şekil 2) (Tziperman ve Malenotti Rizzoli, 1991). Çalışılan plajlar açısından etkili olan rüzgar yönü GB-BGB ve hızı 5-20 m/s'dir. Kıyıya ulaşan dalga yönleri ise G-GB olup dalga yüksekliği ortalama 0-1 $\mathrm{m}$ arasındadır ve kış ve ilkbahar mevsimlerinde 6-7 m ye ulaşır (Özhan ve Abdalla, 2002). Y1llık ortalama gel-git seviye fark1 ise $20 \mathrm{~cm}$ 'yi geçmemektedir (Alpar vd., 2000). Tüm bu faktörler plajların dokusunu belirlemede önemli rol oynamaktadır. 

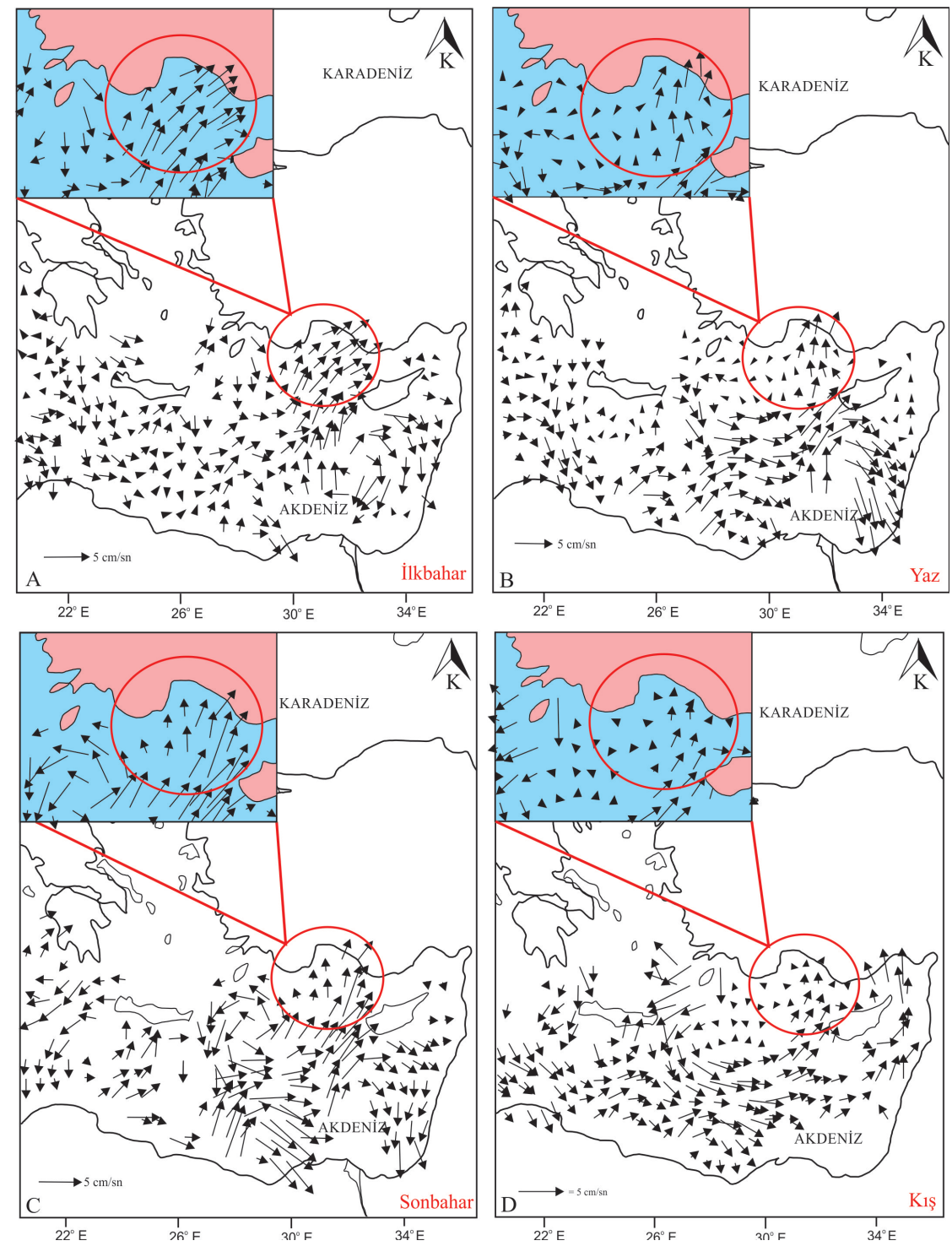

Şekil 2. Doğu Akdeniz akıntı sisteminde mevsimlere bağlı meydana gelen değişimler (Tziperman ve Malenotti Rizzoli, 1991'den değiştirilerek alınmıştır). Şekilde kırmızı daire içerisindeki bölümler Antalya Körfezi'ndeki akıntı yönünü göstermektedir.

Figure 2. Seasonal changes in the Eastern Mediterranean current system (modified from Tziperman and Malenotti Rizzoli, 1991). Red circles in figure show current directions in the Antalya bay.

\section{YÖNTEM}

Çalışma kapsamında örnekleme ve gözlemler hem yaz hem de kış mevsimlerinde Ağustos 2013 ve Şubat-Mart 2014 tarihleri arasında yapılarak tamamlanmıştır. Su altındaki değişimler ise şartların elverişli olduğu durumlarda kıyıdan itibaren ilk 20 m lik kısımda su altından örnekler alınarak izlenmiştir. Her iki plajda da $4,5 \mathrm{~km}$ lik kısımlarda çalışmalar gerçekleştirilmiş, Konyaaltında Boğaçay'dan KD yönünde falezlere kadar, Lara'da ise falezlerin bitiminden doğuya doğru 4,5 km'lik bir hat boyunca incelemeler 
yapılmıştır. Örneklemeler kıyıya paralel 250 m’de bir, kıyıya dik yönde 20 m'de bir olup, her noktadan yaklaşık $2 \mathrm{~kg}$ örnek alınmıştır (Şekil 3). Elde edilen 100 örnek laboratuvarda elek analizine tabi tutulmuştur. Tane boyu sinıflaması ise Wentworth (1922)'ye göre yapılmıştır. Elde edilen sonuçlarla GRADISTAT 4.0 (Blott, 2000) ile tane boyu parametreleri hesaplanmıştır. Bu hesaplamalarda Folk ve Ward (1957) formülleri kullanılmıştır. Toplanan çakılların küresellikleri ise Sneed ve Folk (1958)'a göre hesaplanmıştır. Ayrıca inceleme döneminde plajlardaki jeomorfolojik değişimler gözlemlenmiş ve berm yüksekliğii, plaj eğimi, plaj genişliği ölçümleri yapılmıştır.

\section{BULGULAR}

Kıyı gerisini temsil eden modern plaj örneklerinden elde edilen elek analizi sonuçlarına göre Konyaaltı plajinda ince kum boyundan (\% 0,1-6,7), kaba çak1l boyuna kadar (\% $\%$ 0,6-33,4) sediman bulunmaktadır. Ayrıca elek analizi yapılamayan örneklerde elle yapılan ölçümlere göre tane çap1 (a-ekseni) $10 \mathrm{~cm}$ ye ulaşan taneler mevcuttur. Genel olarak orta ve ince çakıl boyu sedimanların baskınlığ 1 söz konusudur (Şekil 4). Konyaaltı plajı örneklerinin \% 74'ü unimodal, geri kalanı ise bimodal dağılım göstermektedir. Her bir parametre için tüm örnek değerleri kullanılarak oluşturulan grafikte en anlamlı sonuç ortalama tane boyu (Mz) grafiğinde görülmüştür (Şekil 5). Mz için en küçük değer $-3,33 \phi$ en büyük değer ise $0,82 \phi$ (kaba kum) dir. Şekil 5'deki grafikten görüleceği üzere örneklemeye başlangıç noktası olan Boğaçay’ın girişinde (Örnek 1) Mz değerleri kum boyuna yakın iken, buradan uzaklaşıp, falezlere doğru gidildikçe (Örnek 43) tane boyu büyümektedir. Aynı durum So, Sk, Kg için söylenememektedir. $\mathrm{Bu}$ üç parametre kendi içlerinde bazı noktalar hariç birbirine yakın değerler almaktadır. Örneğin So değerleri $0,44-1,90 \phi$ aralığında değişmekte ve örneklerin çoğunda orta-iyi ve orta derecede boylanma tespit edilmiştir.

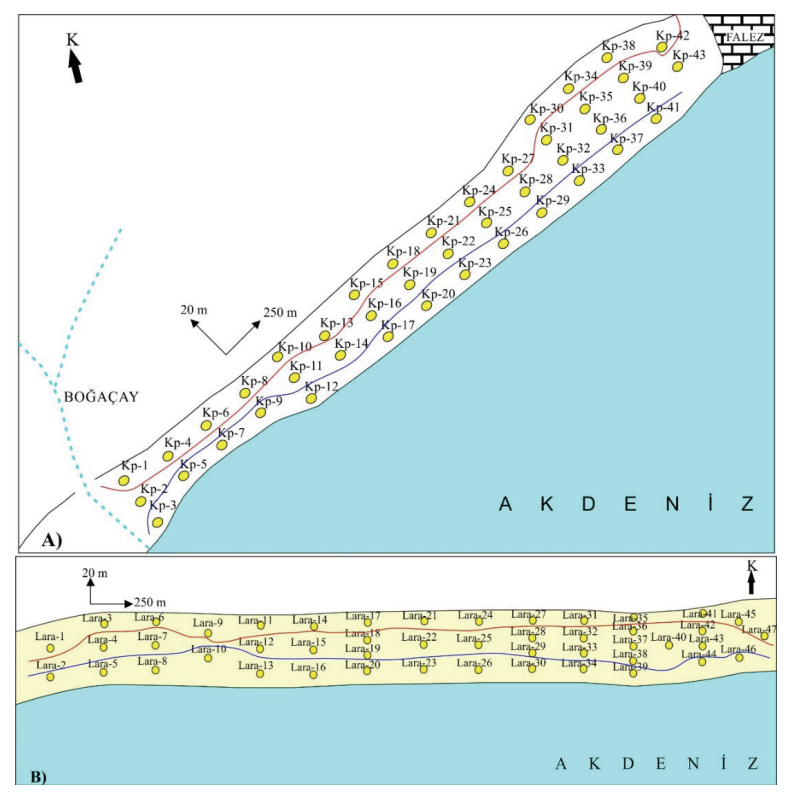

Şekil 3. A) Konyaaltı plajı örnek alım yerleri. Kırmızı çizgi plaj gerisindeki örnekler için sınırı, mavi çizgi ise plaj önü örnekleri için sınırı temsil etmektedir. B) Lara plajında örnek alım yerleri.

Figure 3. A) Sample locations of the Konyaalt beach.Red and blue lines represent boarders for the back beach and front beach samples, respectively. B) Sample locations of the Lara beach. 
Elde edilen sonuçlar plaj gerisi ve önü olarak gruplandırılmıştır (Şekil 3). Burada plaj gerisi ve önü olarak ayrilan kisımlar morfolojik olarak arka plajın (backshore) kıyı çizgisine uzak (geri) ve yakın (ön) noktalarını temsil etmektedir. $\mathrm{Bu}$ gruplar kendi içinde grafiğe aktarıldığında daha anlamlı sonuçlar vermiştir. Öncelikle plaj gerisindeki örneklerde, plaj önüne göre daha küçük, kum boyu sedimanlar bulunmaktadır. Bir diğer husus ise, tekrar başlangıç noktasından merkezde yer alan falezlere doğru gidildiğinde plaj gerisindeki örneklerde net tane boyu artışı söz konusudur (Şekil 6). Plaj önünde ise genellikle tane boyu artan azalan bir gidiş izlemektedir. Ancak bu değişimlerin aralığı düşük ve çakıl boyudur (Şekil 6). Diğer parametrelerde ise çok önemli değişimler gözlenmemiştir. Arazi gözlemlerinde ise Boğaçay'ın hemen yakınında tek basamak şeklinde berm oluşumu gözlenmiştir. $\mathrm{Bu}$ yapı plaj boyunca izlendiğinde, plajın ortalarında daha fazla yükselime sahip olmakla birlikte, basamak sayısı falezlere doğru artış göstermiştir. En son falez önlerinde ise bu yapıların yüksekliği $160 \mathrm{~cm}$ ye ulaşmıştır (Şekil 7). Bunların dışında Konyaaltı plajında örneklemeye başlanılan noktadan, plajın batısından itibaren çakıllarda zonlanmalar tespit edilmiştir (Şekil 8). A zonunda bulunan çakılların boyu $8,4 \mathrm{~cm}$ ye ulaşırken, devamında $\mathrm{b}$ zonunu temsil eden tepecikte ince çakıla geçilmektedir. $\mathrm{Bu}$ yapının hemen önünde ise tekrar çakıllar büyümekte, ikinci basamağın tepesinde tekrar incelmektedir. Bu şekilde en son su içerisine girişte çakıllar büyümektedir. Belirlenen zonlardaki çakılların küresellikleri ise en gerideki zonda 0,47 ile 0,77 arasında değerler alırken, basamak önlerinde 0,52-0,83 e çıkmakta ve diskoidallikleri azalmaktadır. Örnekleme döneminde plajdaki genel doku bu şekilde iken, Temmuz 2014 de iki hafta süren aşırı dalgalı dönemde çalkantı zonunda ince malzemenin arttığ gözlemlenmiştir.

Lara plajında elde edilen bulgulara göre sediman boyu çok kaba kum (-1 / $0 \phi)$ ile çok ince kum (3-4 $\phi)$ arasında değişmektedir (Şekil 4). Şekil 4 'teki grafikten görüleceği üzere plaj ortalarında kaba kum miktarında artış meydana gelmektedir. Lara plaj1 örneklerinin \% 61'i unimodal, geriye kalanlar ise bimodal dağılım göstermektedir. $\mathrm{Bu}$ plaja ait sedimanlarda $\mathrm{Mz}$ değerleri -0,43 $\phi$ ile $1,81 \phi$ arasında değişmektedir. Negatif $\phi$ değerlerini sadece 20-26-30 numaralı örnekler almaktadır ve bu örnekler plajın orta noktasını temsil etmektedir. Tüm örnekler için hesaplanan tane boyu parametrelerinin (Mz, So, Sk ve $\mathrm{Kg}$ ) değerleri kendi içlerinde yakın değerler almaktadır. Konyaaltı plajında tane boyu güneybatı-kuzeydoğu yönünde gidildikçe artarken, Lara plajında bu tip bir değişim görülmemiştir. Ancak tane boyunun burada kum ve alt sınıflarında olması boylanmayı beklendiği şekilde etkilemiş ve örneklerin \% 60’1nda kötü boylanma tespit edilmiştir. 

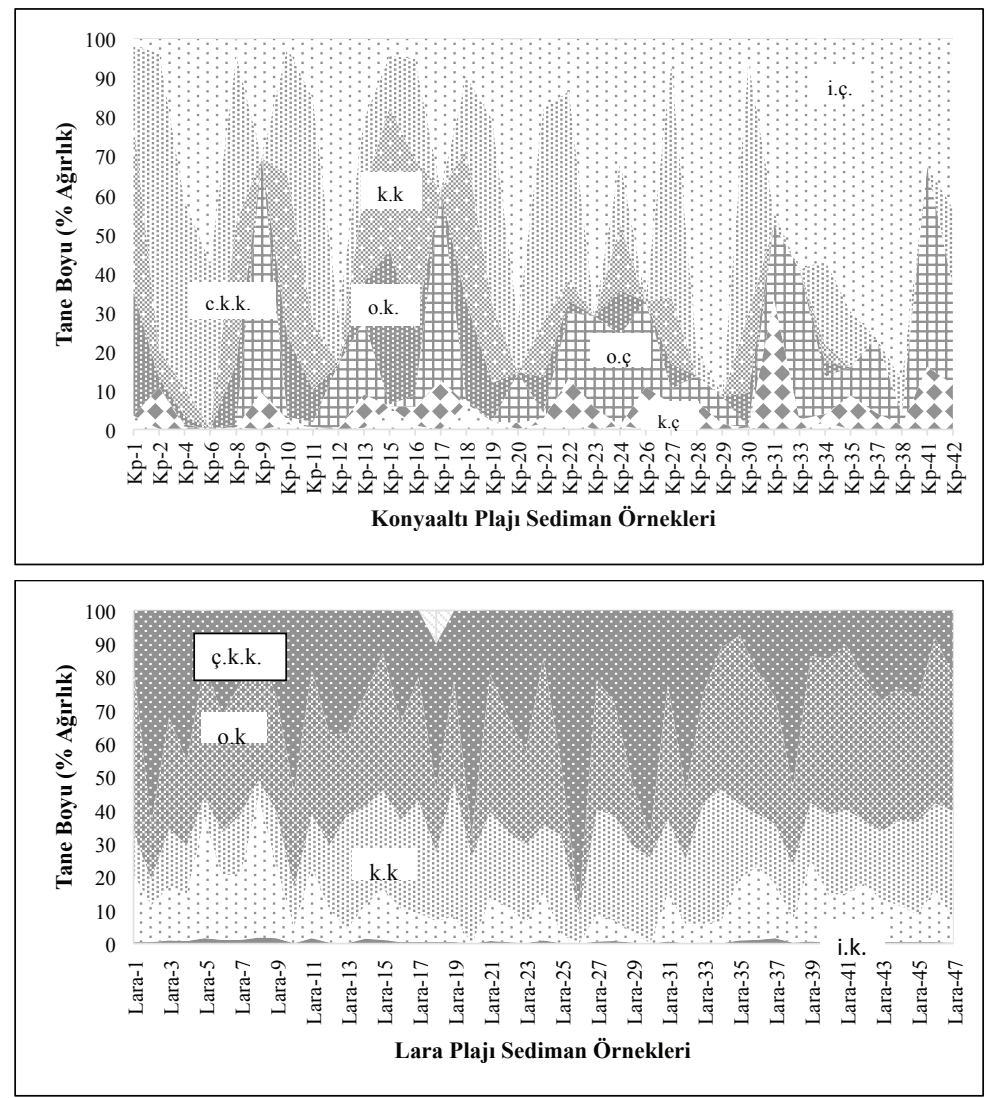

Şekil 4. Konyaaltı ve Lara plaj sedimanlarının tane boyu dağılım grafikleri. (i.k.: ince kum, o.k.: orta kum, k.k.: kaba kum, ç.k.k.: çok kaba kum, i.ç.: ince çakı1, o.ç.: orta çakıl, k.ç.: kaba çakıl)

Figure 4. Graphics showing grain size distribution in the Konyaalt and Lara beach sediments (i.k.: fine sand, o.k.: medium sand, k.k.: coarse sand, ç.k.k.: very coarse sand, i.ç.: fine gravel, o.ç.: medium gravel, k.ç.: coarse gravel)

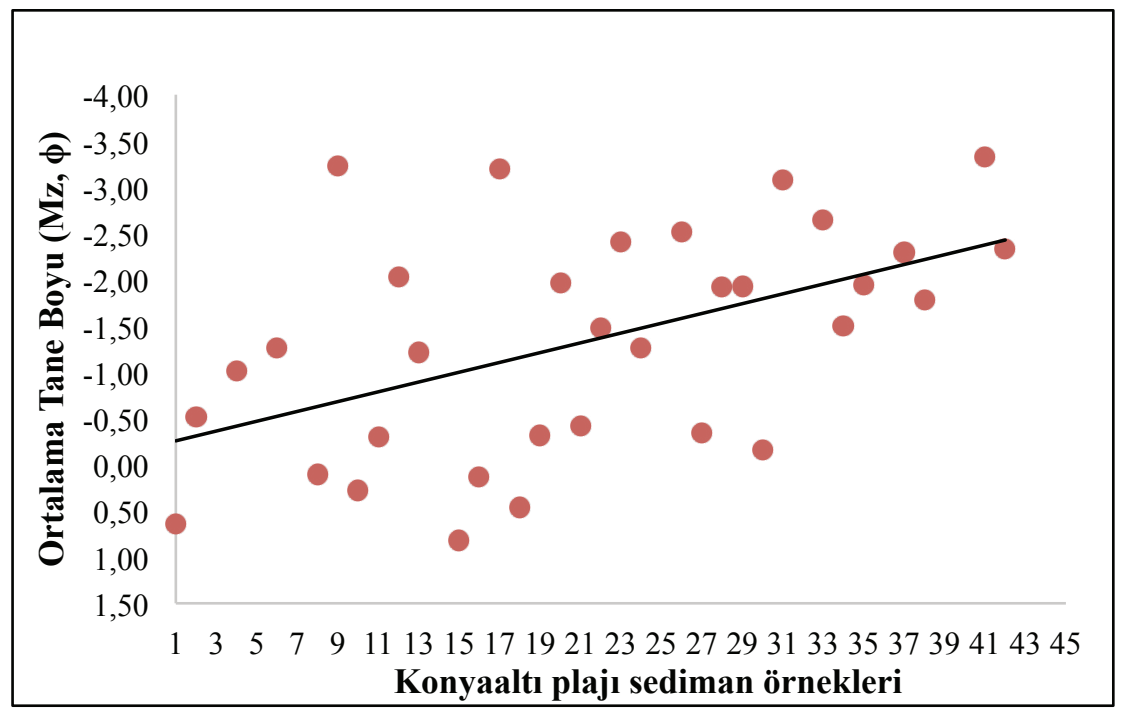

Şekil 5. Konyaaltı plajı sedimanlarında ortalama tane boyu (Mz) değişimi.

Figure 5. Mean grain size (Mz) variation along the Konyaalt beach. 

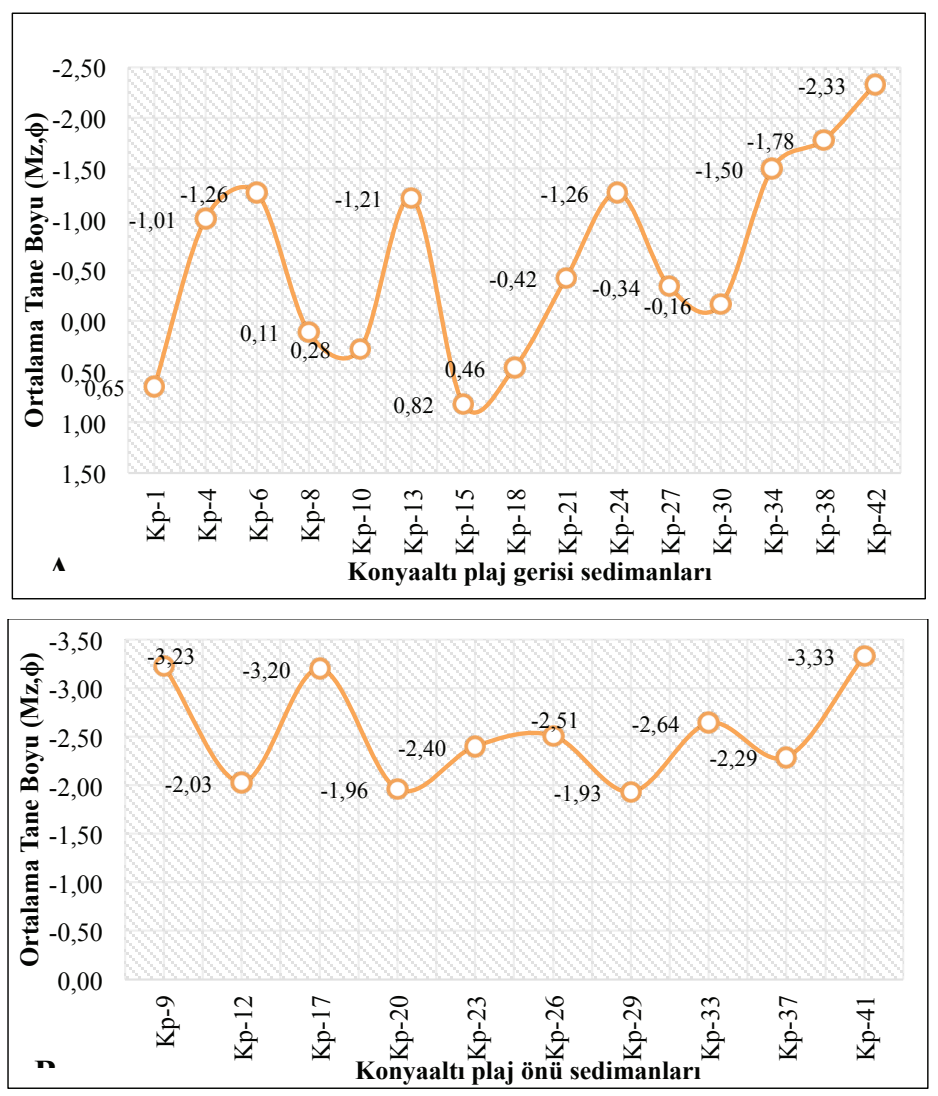

Şekil 6. Konyaaltı plaj gerisi (A) ve plaj önü (B) örneklerinin Mz grafikleri.

Figure 6. Mz graphics of the Konyaalt back beach (A) and front beach (B) samples.

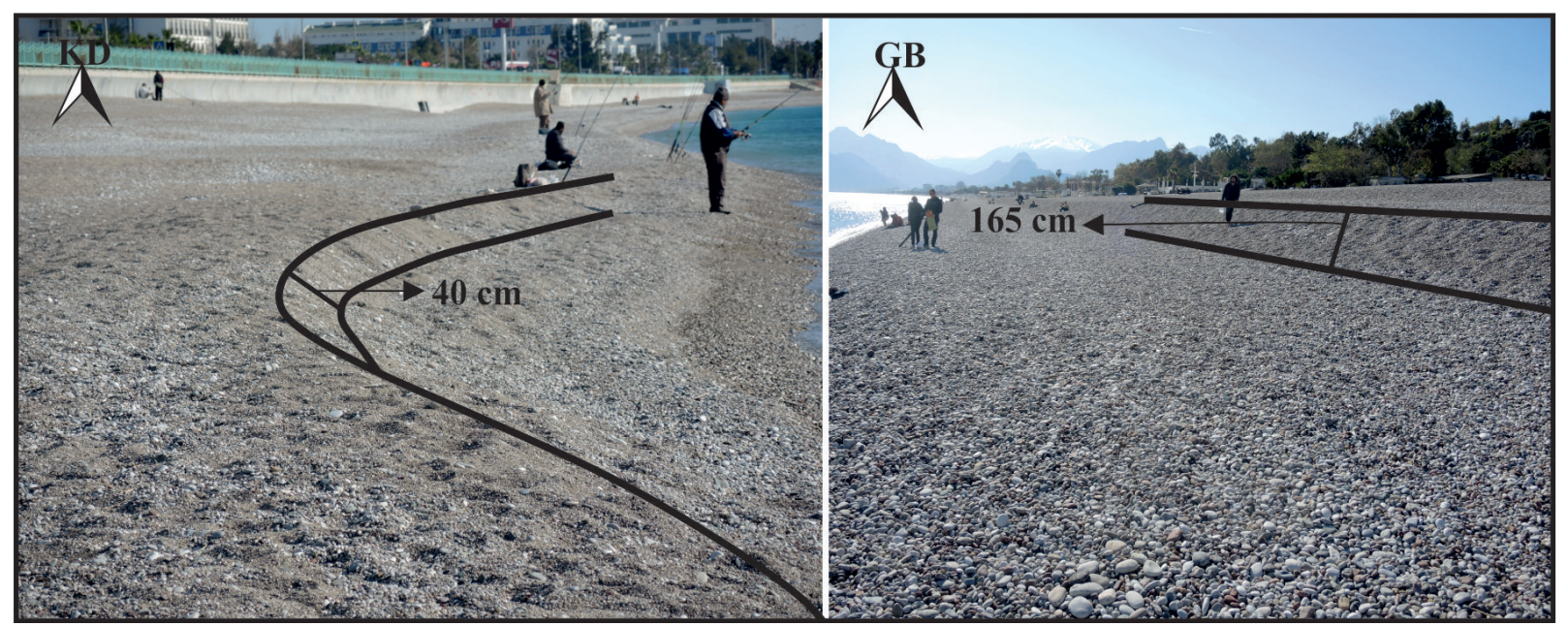

Şekil 7. Konyaaltı plajında bermlerin değişimi

Figure 7. Changes of berms in the Konyaaltı beach. 


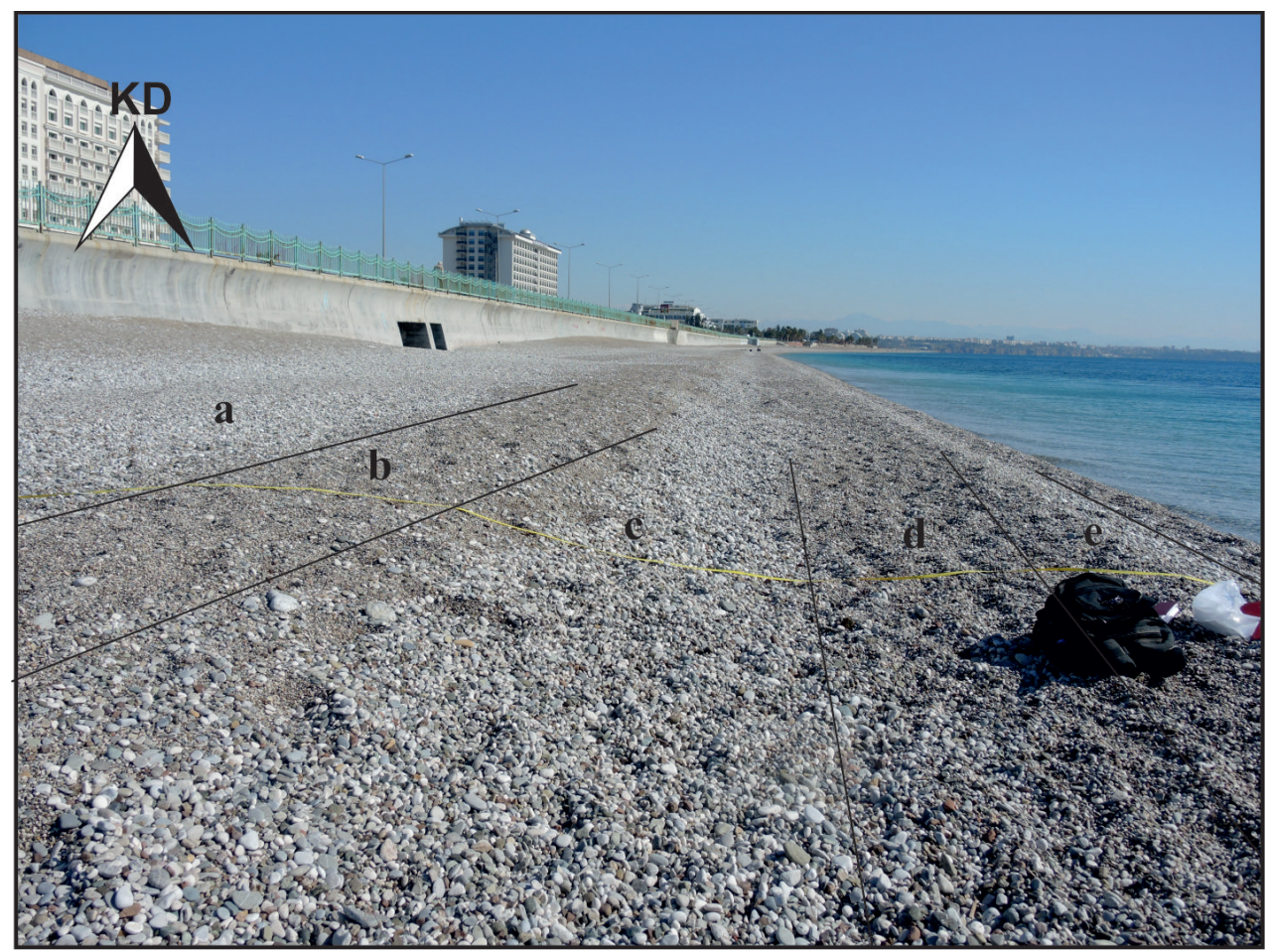

Şekil 8. Konyaaltı plajında zonlanmalar, a,c ve e zonları kaba çakılları, b ve d zonları ise ince çakılları göstermektedir.

Figure 8. The zonations in the Konyaalt beach, a,c and e zones show coarse gravel, $b$ and $d$ zones show granules.

Lara plajına ait sonuçlar plaj önü ve gerisi şeklinde gruplandırıldığında önemli bir özellik görülmüştür. Hem plaj gerisi hem de plaj önü örneklerinde, $\mathrm{Mz}$ grafiklerinde ritmik artma ve azalma görülmektedir (Şekil 9). Mavi oklar ve kırmızı elipslerle de gösterilen bu değişim kıyıya ulaşan dalgaların hareketine birebir benzemektedir (Şekil 9). Bunun dişında plaj gerisindeki örneklerde $\mathrm{Mz}$ değerleri $0,74-1,40 \phi$ arasında iken, plaj önünde bu değer aralığ $1-0,43$ ile 1,80 $\phi$ aralığında ilerlemektedir. Buradan plaj gerisinden önüne doğru tane boyunda artış gerçekleştiği söylenebilir. Boylanmada ise plaj gerisinde değerler düz bir hat takip ederken, plaj önüne gelindiğinde büyük sapmalar göstermektedir. $\mathrm{Bu}$ da plajın kıyıya dik yönde tane boyunda değişim meydana geldiğinin diğer bir göstergesidir. Lara plajında morfolojik değişimler mevsimlere göre önemli farklılıklar göstermiştir. Örnekleme döneminde homojen bir görünümde olan plaj yüzeyi, kış ve ilkbahar mevsimlerinde plaja gelen çakıllar ile birlikte zonlanmalar göstermiştir (Şekil 10). Bu zonlardaki çakılların ortak özellikleri c eksenlerinin çok küçük olması ve bu nedenle ileri derecede diskoidallik sergilemesidir. Konyaaltı plajındaki çakılların daha küresel olduğu daha önce belirtilmişti. Bu bölümlerdeki çakıllar ile ilgili olarak diskoidalliklerinin dışında gözlemlenen diğer bir özellik, kıyı çizgisine yakın olan zondaki çakıllar daha çubuksu şekildedir. Kıyıdan uzaktaki ikinci zonda ise dairesel çakılların hakimiyeti söz konusudur.

Açılan araştırma çukurları düşey yöndeki değişimi ortaya çıkarmıştır. Çukurlar 
kıyı çizgisine yakın (15 m) ve uzak (30 m) olacak şekilde açılmıştır. Yakın olan çukurlarda yüzeyden itibaren çakıl ve kumlu seviyelerin ardalandı̆̆ tespit edilmiştir. Çakıllı seviyeler 1-6 cm kalınlığa sahip iken, kumlu seviyeler 0,5-2 cm aralığında değerler almaktadır (Şekil 11). Şekil 11'den görüleceği üzere çakıllı seviyelerde çakıllar c eksenleri boyunca üst üste dizilmiş, karmaşık bir yapıdan daha çok düzenli bir görünüm sergilemektedir. Uzak olan çukurlarda ise farklılık söz konusudur. İlk $40 \mathrm{~cm}$ de tamamen kum boyu malzeme varken, araya $5 \mathrm{~cm}$ 'lik çakıllı bir seviye girmekte, daha sonra ise yine kum olarak devam etmektedir (Şekil 11). Bu tip bir durum değişen mevsim koşullarında çakılların kış ve ilkbahar mevsimlerinde plaja biriktirildiğini ve bunun plajın kıyı çizgisinden itibaren ilk 20 m lik kısımda daha net görülebildiğini göstermektedir.

\section{TARTIŞMA VE SONUÇLAR}

İncelenen iki plajın ortalama tane boyu, boylanma, çarpıklık ve tepelenme değerleri birbirinden tamamen farklıdır. Bu durum Mz-So ve Mz-Sk grafiklerinden açıkça görülmektedir (Şekil 12). Her iki plajın değerleri kendi arasında gruplanmaktadır. Bu tarz yaklaşım daha önceki çalışmalarda (Folk ve Ward, 1957; Friedman, 1967) akarsu ve plaj sedimanları için uygulanmıştır. Bu nedenle burada sorulması gereken soru, aynı kıyı boyu akıntı ve dalga sistemi içerisinde yer alan iki plajın neden farklı tane boyu ve şekillere sahip olduğudur.

Erginvd.(2007)körfezinbatıvedoğusunda yer alan plajlardaki farklılıkları kıyı ardındaki topoğrafya, akarsuların fiziksel özellikleri ve kıyı morfolojisi ile açıklamış, doğudaki plajların ince taneli olmasında doğu yönlü taşınmanın etkili olabileceğini belirtmiştir. Konyaaltı plajının hemen gerisinde yükselimlerin olması buradaki akarsuların daha enerjik akması ve daha büyük sediman taşıması gerektiğini düşündürebilir. Bu tarz bir yaklaşım yanlış değildir fakat burada buna ek olarak daha çok taşınan sedimanın özelliği ve taşınma mesafesi önemlidir. Ayrıca akarsuların taşıyacakları malzeme eğimle doğru orantılı değildir (Chatanantavet ve Lamb, 2014). Boğaçay ve Aksu çayını karşılaştırdığımızda Boğaçay daha kısa mesafede kıyıya ulaşmaktadır ve taşınan malzemenin aşınmak için yeterli zaman/ mesafesi yoktur. Taşınan sedimanın özelliklerine gelindiğinde batıda ağırlıkla kireçtaşı ve Antalya naplarının içerisindeki ofiyolitik birimler, doğudaki Miyosen havzası klastikleri ve Alanya metamorfitlerine göre daha dayanıklıdırlar. Bu da Konyaaltı plajında çakı1lı malzemenin baskın olmasında diğer önemli nedendir.

Yapılan çalışmada Konyaaltı plajında KD yönünde ortalama tane boyunda artış (Şekil 9) tespit edilmiştir. Bu durum kıyı boyunca oluşan akıntılar ve dalga taşımasının sonucudur (Şekil 13). Genel kabul taşınma yönünde tane boyunun küçüleceği yönündedir. Fakat bu dinamik kıyılarda geçerli değildir. En azından kıyıya paralel yönde çalışmamaktadır. Son yıllarda ince ve kaba çakıllardan oluşan plajlarda yapılan araştırmalarda kıyıya paralel yönde kaba çakılların, ince çakıllardan daha uzağa taşındığ 1 tespit edilmiştir (örn. Alan vd., 2006; Curtis vd., 2011; Dickson vd. 2011; Miller vd., 2011). Bu durumu Nicholls ve Wright (1991) büyük çakılların daha hızlı hareket etmesiyle, Osborne (2005) ise küçük çakılların büyük çakıllar arasında takılıp geri kalmasıyla açıklamıştır. Bir diğer neden şu olabilir, kıyıya ulaşan dalgalar ani olarak kırılırlar ve büyük çakılların daha büyük yüzeye sahip olması bu etkiyi daha fazla hissedilmesine neden olur. Böylece büyük çakıllar daha düzenli hareket ederken, küçükler düzensiz bir şekilde dağılmakta ileri ve geri dalga hareketleri ile savrulmaktadır. Doğu yönlü taşınma söz konusu iken Lara plajında kum 
olmasının nedenine gelindiğinde, burada falezler devreye girmektedir. Falezler merkezde kalıp engel görevi görmekte ve çakılların taşınmasının devam etmesini engelleyerek malzemenin Konyaalt1 plajında birikmesine neden olmaktadır. Bu durum falezlere yaklaştıkça bermlerin büyümesi ile de açıklanabilir. Buna benzer örnekleri Yeni Zelanda da görmek mümküdür (bknz. Ivamy ve Kench, 2006).

Elde edilen sonuçlardan bir diğeri kıyı çizgisine dik yönde tane boyu ve tane şeklinde tespit edilen değişimlerdir. Konyaaltı ve Lara plajlarında kıyı çizgisine doğru tane boyu artmaktadır. Lara plajında kıyı çizgisine yakın bölgelerdeki çakıllar çubuksu, uzakta olanlar ise daireseldir. Tane boyunun kıyı çizgisine doğru büyümesi Horn ve Walton (2007) tarafından belirtilmiş, tane şekli ile ilgili değişimlere ise Bluck (1967) ve Orford (1975) dikkat çekmiştir. Buscombe ve Masselink (2006), Bluck (1967)'ın çalışmasını ve bunu destekleyen görüşleri varsayımsal olarak nitelendirse de, Antalya plajlarında yapılan bu çalışmada elde edilen sonuçlar da Bluck (1967) ve Orford (1975)'in bulgularını destekleyici niteliktedir.

Son olarak plajların sedimantolojik dokusu göz önüne alınarak sınıflaması yapıldığında bazı sorunlar ortaya çıkmaktadır. Öncelikle Jennings ve Schulmeister (2002)'in siniflamasina göre, Ergin vd (2007) batıdaki plajları çakıllı, kum-çakıl karışık, doğudaki plajları ise kumçakı1 karışık olarak sınıflamıştır. Lara plajı bu sınıflamaya uymaktadır ve kum-çakıl karışık plaj türündedir. Konyaaltı plajı ise genel olarak çakıllı plaj gibi olsa da, plajın incelenen bölümlerinde geri kısımları kumlu zonlardan oluşmaktadır. Bu durumda kum-çakıl karışık plaj denebilir. Fakat bu da sorunludur. Çünkü var olan sinıflamada plajın bu şekilde sınıflanması için hem yatay hem de düşey yönde kum-çakıl karışık halde olması gerekmektedir. Burada ise düşey yönde kum görülmemektedir. Sonuç olarak Konyaaltı için yeni bir isimlendirme gerekmektedir.

Antalya merkezinde yer alan Konyaaltı ve Lara plaj1 birbirinden tamamen farklı fiziksel özellikler sunmaktadır. Bu farklılıkların oluşmasında akarsu rejimleri, kıyı ardı kaynak alan ve topoğrafyası, kaynak litolojisi, kıyıda hidrodinamik (dalga ve akıntılar) ve morfodinamik (plaj profilleri) özellikler birlikte rol oynamaktadır. Plajlar mevsimlere bağlı olarak önemli farklılıklar göstermektedir. Konyaaltı plajında genelde çakılların taşınması ve birikmesi söz konusudur. Lara plajı kum çakı1 karışık plaj sınıfina girerken, Konyaaltı plajında yeni bir sınıflamaya ihtiyaç duyulmaktadır. Buçalışma kapsamında çoğunlukla fiziksel özellikler üzerinde durulmuştur. Fakat bu alanlardaki dinamiklerin anlaşılması için detaylı hidrolojik çalışmaların mutlaka yapılması ve bu sonuçlarla birleştirilmesi gerekmektedir. 

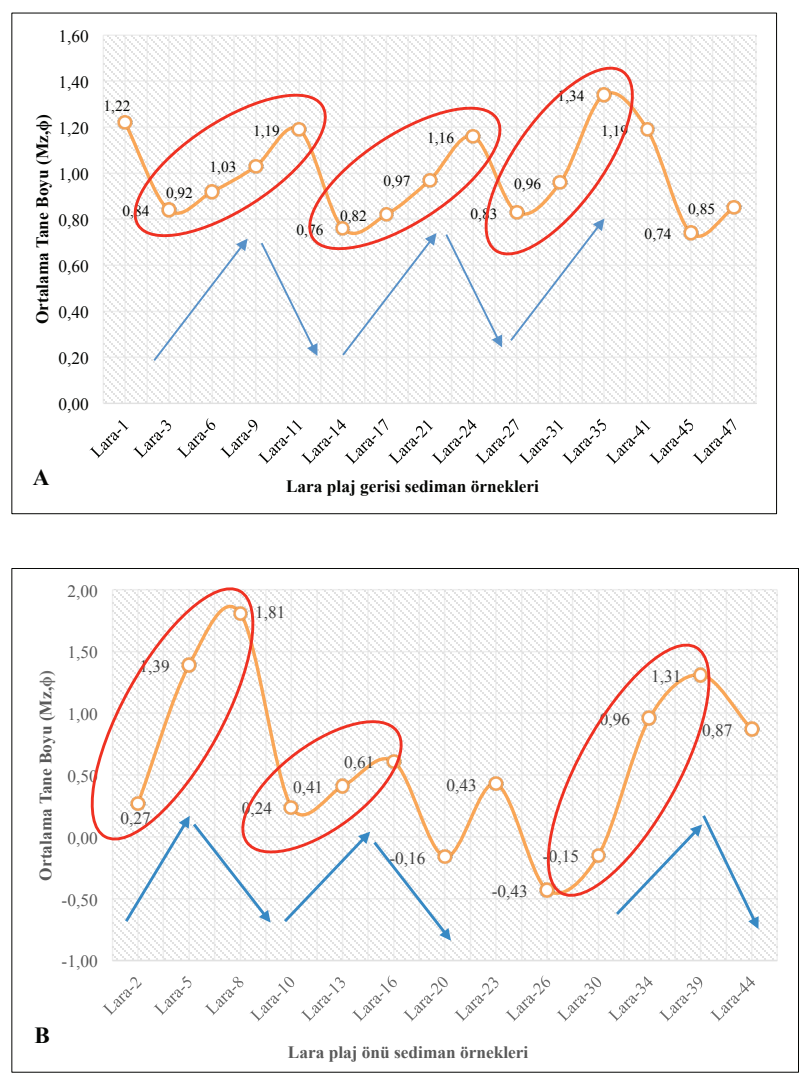

Şekil 9. Lara plaj gerisi (A) ve plaj önü (B) örneklerinin Mz grafikleri. Şekildeki kırmızı elips ve oklar tane boyundaki değişim ile dalga hareketleri arasındaki ilişkiyi göstermektedir.

Figure 9. Mz graphics of the Lara back beach (A) and front beach (B) samples. Red ellipes and arrows are showing that relation between grain size variation and wave movements.

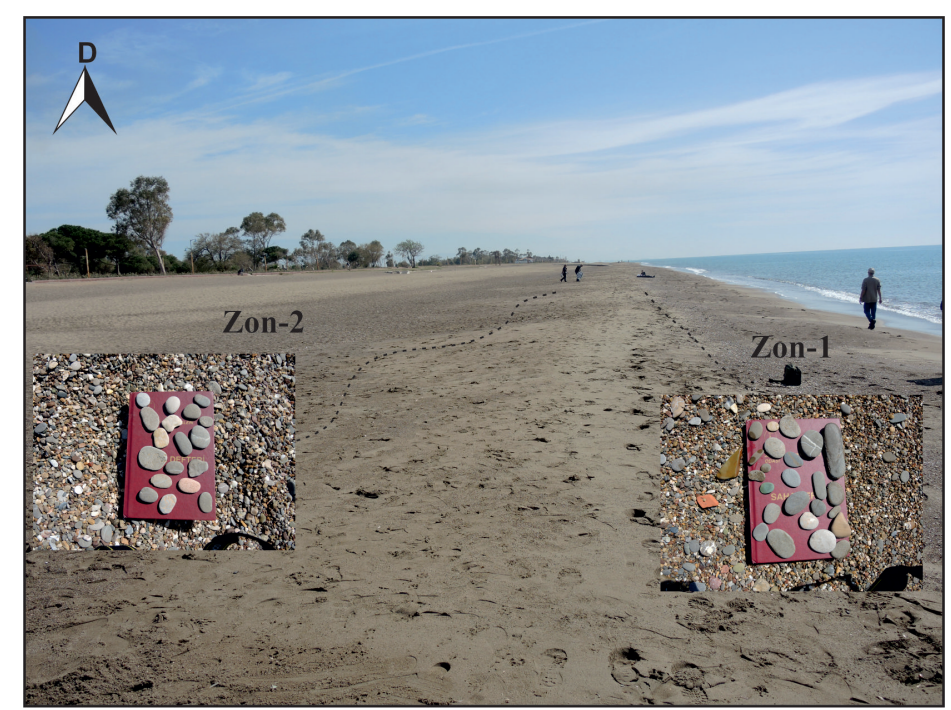

Şekil 10. Lara plajında gözlemlenen tane boylarındaki zonlanma

Figure 10. Grain size zonation observed in the Lara beach 

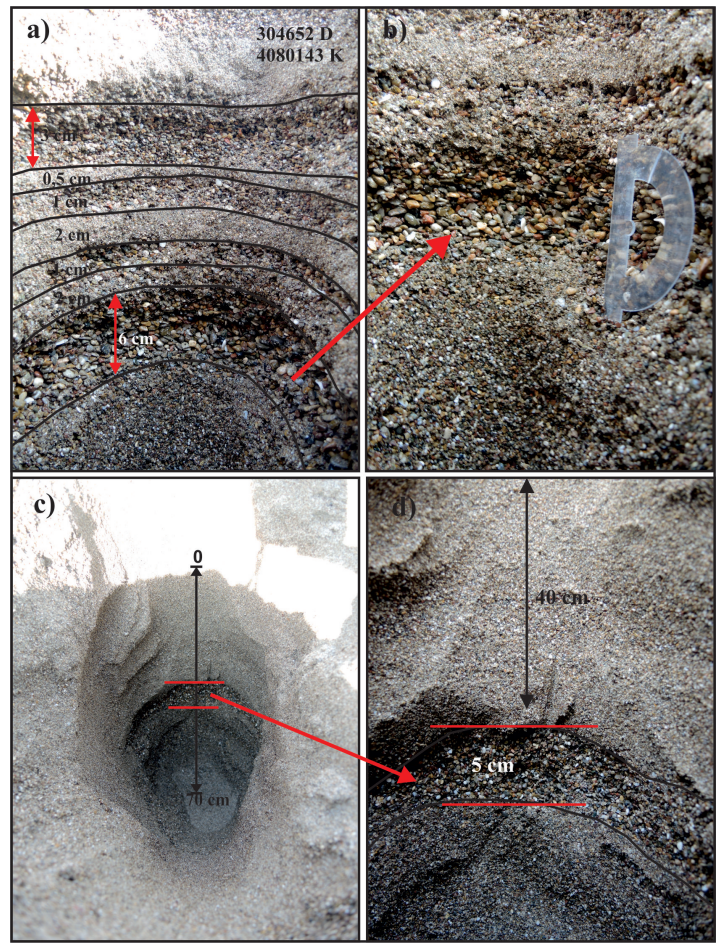

Ş̧ekil 11. Lara plajında açılan araştırma çukurları. (a/b) Kıyı çizgisine yakın açılan çukurun düşeydeki değişimi gözlenmektedir. (c/d) Kıyı çizgisinden 30 m uzakta açılan çukur görülmektedir.

Figure 11. Research pits excavated in the Lara beach. Photo shows the vertical variation in pit that excavated near shoreline $(a / b)$. Excavated pit $30 \mathrm{~m}$ far away from the shoreline $(c / d)$.

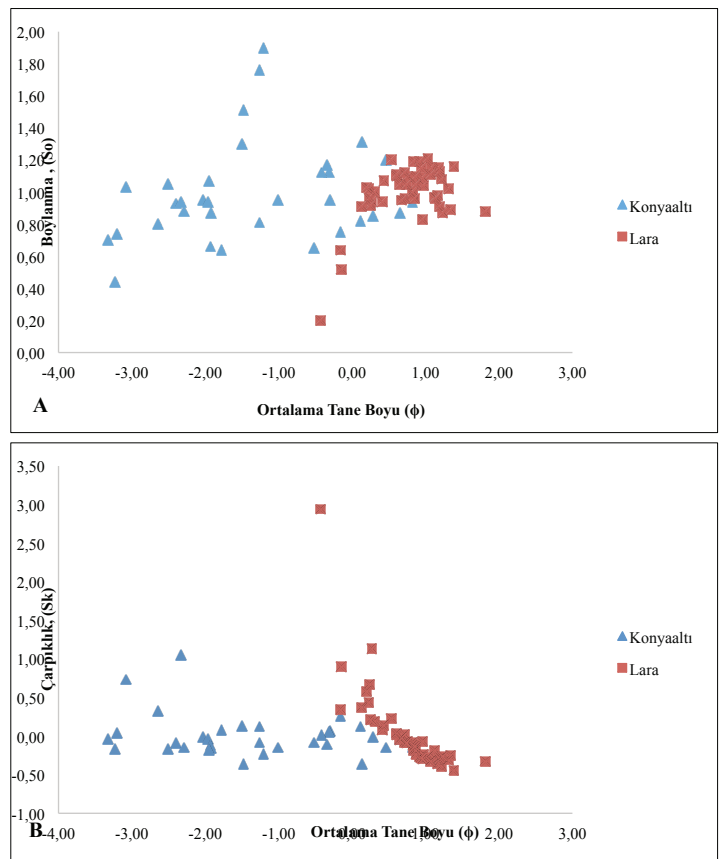

Şekil 12. ̇̉ki plajın Mz değerlerine karşılık So (A) ve Sk (B) değerleri grafiği

Figure 12. Crossplots of Mz versus So (A) and Mz versus Sk (B) in the Konyaaltı ve Lara beach sediments. 

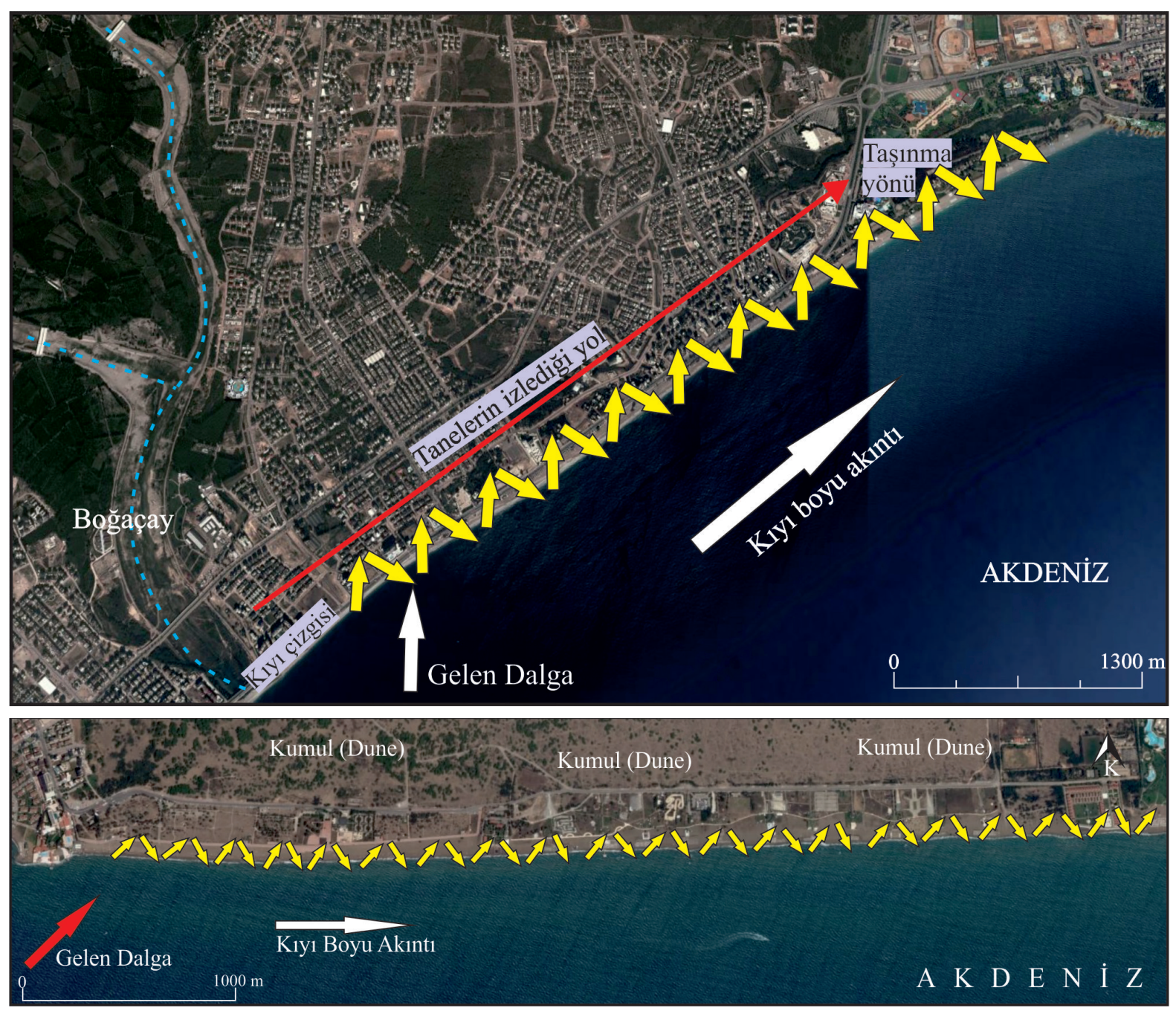

Şekil 13. Konyaaltı ve Lara plajı kıyısında akıntı ve tanelerin taşınma modeli

Figure 13. Longshore current and sediment transportation model of the Konyaalt and the Lara beach

\section{KATKI BELIRTME}

Bu çalışma birinci yazarın Akdeniz Üniversitesi Fen Bilimleri Enstitüsü'nde 2014 y1lında tamamladığı yüksek lisans tez çalışmasının bir bölümünü içermektedir. Yazarlar çalışmanın gerçekleştirilebilmesi için gerekli desteği sağlayan Yüksek Öğretim Kurumu Öğretim Üyesi Yetiştirme Programına (ÖYP), tez çalışması sırasında değerli görüş ve eleştirileriyle katkı sağlayan Nizamettin Kazancı'ya (AÜ), makalenin ilk düzeltmelerinde eleştiri ve önerileriyle destek veren Alper Gürbüz'e (NÜ), arazi çalışmalarına katılan Ferdi Demirtaş, Halil Bölük ve Fatih Uçar'a (AKD. Ü.), ve tez çalışması hakkında değerli görüş ve önerileriyle katkı sağlayan Fuzuli Yağmurlu'ya (SDÜ), önemli eleştiri ve önerileriyle makalenin son halini almasını sağlayan Mustafa Ergin (AÜ) ve Muhsin Eren'e (MÜ) teşekkür ederler. 


\section{EXTENDED SUMMARY}

Physical features of sediments such as mean grain size, sorting, skewness and kurtosis have great importance in sedimentological investigations. These parameters depend on depositional environment and hydrological conditions. In this study, these features were examined in the Konyaalt and Lara Beaches of Gulf of Antalya. The Gulf of Antalya has a reverse-V-shaped geometry. Its geometry has shaped and controlled by the tectonics of the Aegean-Cyprian arc in the Mediterranean Sea. Along the coasts of the gulf, there are numerous beaches. Despite their reputations in the meaning of tourism, these beaches are not studied in detail within sedimentological approaches except Ergin et al. (2007). The purpose of our study is to examine sedimentological features of the Konyaalt and Lara beaches in detail and classify them. These beaches are located in the west and in the east of Antalya city centre, respectively, on both flanks of the gulf.

In the literature, there are many classification studies for beaches. Jennings and Schulmeister (2002)'s classification is the wide-excepted and commonly used one among those studies. According to their classification; beaches are divided into three groups as follows: (1) pure gravel, (2) mixed sand and gravel, and (3) composite beaches.

In order to our aforementioned purposes, 100 samples were collected from modern surfaces in the backshores of the Konyaalt and Lara beaches. For the determination of grain size parameters surficial samples were collected in summer and spring months of 2013 and 2014. Samples were added to $10 \% \mathrm{H}_{2} \mathrm{O}_{2}$ to remove the organic matter and then grain size analyses were carried out using standard sieving methods. Grain size features described by Folk and Ward (1957) were used to define grain size distributions as a summation of the degree of mixing of modal populations. According to our results, the mean grain sizes in the Konyaalt beach vary between -3,50 $\phi$ and $0,82 \phi$. On the other hand sorting values range from $0,44 \phi$ to $1,90 \phi$, skewness values vary from - 0,36 to 1,05, and kurtosis values range between 0,33 and 2,56. In the Konyaalt beach the mean grain size increases from west to east in other parameters, we could not observe any meaningful trend. In the Lara beach, the mean grain sizes for each sampling points range from $-0,43 \phi$ to $1,81 \phi$, sorting values are between 0,20- 1,21 $\phi$, skewness values vary between -0,45 and 2,94, and the kurtosis values are between 0,41-1,46. There are no meaningful spatial variations in the Lara beach.

According to grain size parameters, the Lara beach is classified as mixed sand and gravel beach. The Konyaalt beach is not fit to common classification. Because its sedimentological features are comparable to both composite and pure gravel beach. For this reason it needs a new classification. Due to differences of topography, lithological differences in the drainage area of the stream behind the beaches, they have different sedimentological patterns.

\section{DEĞİNILEN BELGELER}

Alan, J.C., Hort, R. ve Tranquili, J.V. 2006. The use of Passive Integrated Transponder (PIT) tags to trace cobble transport in a mixed sand and gravel beach on the high energy Oregon coast, USA. Marine Geology, 232, 63-86.

Alpar, B., Doğan, E., Yüce, H. Ve Altıok, H. 2000. Seal level changes along the turkish coasts of the Black Sea, the Aegean Sea and the Eastern Mediterranean. Mediterranean Marine Science, 1, 141-156.

Bartholoma, A., Ibbeken, H. ve Schleyer, R. 1998. Modification of Gravel During Longshore Transport (Bianco Beach, Calabria, Southern Italy). Journal of Sedimentary Research, 68 (1), 138-147. 
Blott, S. 2000. A grain size distribution and statistics package for the analysis of unconsolidated sediments by sieving or laser granulometer, GRADISTAT version 4.0.

Bluck, B.J. 1967. Sedimentation of Beach Gravels: Examples From South Wales. Journal of Sedimentary Petrology, 37 (1), 128-156.

Boggs, S. 2011. Principles of Sedimentology and Stratigraphy. Prentice Hall, 600 s. Berlin.

Buscombe, D. ve Masselink, G. 2006. Concepts in gravel beach dynamics. Earth Science Reviews, 79, 33-52.

Chatanantavet, P. ve Lamb, M.P., 2014.Sediment transport andtopographicevolution of a coupledriverandriverplumesystem: An experimentalandnumericalstudy, Journal of GeophysicalResearch - Earth Surface, 119, doi:10.1002/2013JF002810

Curtis, G.M., Osborne, P.D. ve Horner-Divine, A.R. 2009. Seasonal patterns of coarse sediment transport on a mixed sand and gravel beach due to vessel wakes, wind waves, and tidal currents. Marine Geology, 259, 73-85.

Çiner, A., Karabıyıkoğlu, M., Monod, O., Deynoux, M. ve Tuzcu, S. 2008. Late Cenezoic sedimentary evolution of the Antalya Basin, Southern Turkey. Turkish Journal of Earth Science, 17, 1-41.

Dickson, E. M., Kench, S.P., ve Kantor, M.S. 2011. Longshore transport of cobbles on a mixed sand and gravel beach, southern Hawke Bay, New Zealand. Marine Geology, 287, 31-42.

Ergin, M., Keskin, Ş., Doğan, U., Kadıŏlu, Y.K. ve Karakaş, Z. 2007. Grain size and heavy mineral distribution as related to hinterland and environmental conditions for modern beach sediments from the Gulfs of Antalya and Finike, eastern Mediterranean. Marine Geology, 240, 185-196

Ergin, M., Okyar, M., Ediger, V., Keskin, Ş., Günel, H., Tezcan, D. ve Salihoğlu, İ. 2004. Antalya Körfezi kıta sahanlığının Geç Kuvaterner jeolojisi: sedimantolojik, mineralojik, jeokimyasal ve sismik araştırmalar. Proje No: YDABÇAG-199Y074, 132, Erdemli, İçel.

Folk, R. ve Ward, W. 1957. Brazos River Bar: A study in the significance of grain size prameters. Journal of Sedimentary Petrology, 27(1), 3-26.

Friedman, G.M. 1967. Dynamic Process and Statical Parameters Compared For Size Frequency Distribution of Beach and River Sands. Journal of Sedimentary Petrology, 37 (2), 327-354.

Horn, D.P. ve Walton, S.M. 2007. Spatial and temporal variations of sediment size on a mixed sand and gravel beach. Sedimentary Geology, 202, 509-528
Ivamy, C.M. ve Kench, P.S. 2006. Hydrodynamics and morphological adjustment of a mixed sand and gravel beach, Torere, Bay of Plenty, New Zealand. Marine Geology, 228, 137-152.

Jennings, R. ve Shulmeister, J. 2002. A field based classification scheme for gravel beaches. Marine Geology, 186, 221228 .

Kansun, G. ve Baş, H. 2002. Alanya (Antalya) doğusunda Alanya Birliği'nin metamorfik özellikleri. 55. Türkiye Jeoloji Kurultayı Bildiri Özleri, Ankara, 137-138.

Koşun, E. 2012. Facies characteristics and depositional environments of Quaternary tufa deposits, Antalya, SW Turkey. Carbonates and Evaporites, 27 (3-4), 269-289.

Lefevre, R. 1967. Novvel element de la geologie du Taurus Lyccien Les nappes d'Antalya (Turquie). C.R.A.S., 263, 13651368.

Miller, I.M., Warwick, J.A. ve Morgan, C. 2011. Observations of coarse sediment movements on the mixed beach of the Elwha Delta, Washington. Marine Geology, 282, 201214.

Muzuka, A.N. ve Shaghude, Y.W. 2000. Grain size distribution along the Msasani Beach, North of Dar es Salaam Harbour. Journal of African Earth Sciences, 30 (2), 417-426

Nicholls, R.J. ve Wright, P. 1991. Longshore transport of pebbles: experimental estimates of $\mathrm{K}$. Proceedings of Coastal Sediments '91, ASCE, 920-933.

Orford, J.D. 1975. Discrimination of particle zonation on a pebble beach. Sedimentology, 22, 441-463.

Osborne, P.D. 2005. Transport of gravel and cobble on a mixed sediment inner bank shoreline of a large inlet, Grays Harbor, Washington. Marine Geology, 224, 145-156.

Özhan, E. ve Abdalla, S. 2002. Türkiye Kıyıları Rüzgar ve Derin Deniz Dalga Atlası. Kıyı Alanları Yönetimi Türk Milli Komitesi/MEDCOAST, $445 \mathrm{~s}$

Poisson, A., Yağmurlu, F., Bozcu, M. ve Şentürk, M. 2003. New insights on the tectonic setting and evolution around the apex of the Isparta Angle (SW Turkey). Geological Journal, 38, 257-282.

Reineck, H.E. ve Singh, I.B. 1980. Depositional Environments. Springer, 551 s. Berlin.

Robinson, A.,R. vd. 1992. General circulation of the Eastern Mediterranean. Earth Science Reviews, 32, 285-309.

Sneed, E.D. ve Folk, R.L. 1958. Pebbles in Lower Colarado River, Texas. A study in particle morphogenesis. Journal of Geology, 27, 140-150.

Şenel, M. 1997. Türkiye Jeoloji Haritaları Antalya L-11 Paftası. 1:100000 ölçekli, No: 8, MTA, Ankara. 
Tziperman, E. ve Malonette-Rizzoli, P. 1991. The climatological seasonal circulation of the Mediterranean Sea. Journal of Marine Research, 49, 411-434.

Visher, G.S. 1969.Grain size distributions and depositional processes. Journal of Sedimentary Petrology, 39, 1077-1106.
Makale Geliș Tarihi ～: 11 Kasım 2014

Kabul Tarihi : 03 Mart 2015

Received

: 11 November 2014

Accepted

: 03 March 2015 